\title{
Revealing the precipitation dependency of regional in time and in space thermal anomaly peaks in SW USA
}

\author{
George Ch. Miliaresis ${ }^{1}$ (i)
}

Received: 9 February 2016/Accepted: 11 February 2016/Published online: 20 February 2016

(C) Springer International Publishing Switzerland 2016

\begin{abstract}
The selective variance reduction technique that applies linear regression models to the principal components of multi-temporal night monthly averaged land surface temperature (LST) imagery splits the variance associated to elevation, latitude, longitude in SW USA for the year 2007. The reconstructed multi-temporal imagery indicate the positive or negative deviation (thermal anomaly) from the elevation, latitude, longitude predicted LST. The spatial and temporal patterns of thermal anomalies are revealed by $\mathrm{K}$-means clustering. The mean precipitation computed per month per cluster interprets the observed fluctuations in the temporal pattern of thermal anomaly. Thus, it is possible to isolate the regional thermal anomaly component from the residual component induced from local weather phenomena (precipitation and possibly snow melting, surface water flow and water table depth variations). The regional thermal anomaly component is more likely to relate to geology (lithology-thermal inertia of rocks) and geophysics (geothermal fields) in the study area. The influence of precipitation to the temporal pattern of LST could provide a sort of evaluation of the precipitation data sets available.
\end{abstract}

Keywords Land surface temperature - MODIS . Precipitation · DAYMET $\cdot$ Thermal anomalies $\cdot$ Spatial modeling

George Ch. Miliaresis

gmiliar@yahoo.com

1 Open University of Cyprus, 38 Tripoleos Str., Athens 104-42, Greece

\section{Introduction}

Currently land surface temperature (LST) data sets are computed from the satellite-based remotely sensed images with high temporal resolution at a moderate resolution scale, allowing the day and night monitoring of earth's surface (Wan 2013). An example being the LST acquisitions from MODerate-resolution Imaging Spectroradiometer (MODIS) on board the Aqua satellite (Wan 2014).

The identification and mapping of thermal anomalies is a key issue in environmental analysis (Miliaresis 2014b). Miliaresis (2009) defined LST anomalies from a time series of LST imagery as regions presenting significantly higher or lower LST than their surrounding area. LST is correlated to elevation (H), latitude (LAT), and longitude (LON) so the quantification of thermal anomalies in vast regions is difficult (Miliaresis 2012c). In this context, Miliaresis (2012a) presented a method, named selective variance reduction (SVR) for $\mathrm{H}, \mathrm{LAT}$, LON decorrelation stretch of multi-temporal night monthly LST imagery. The method was extended to account for distance form the coastline and applied in vast regions in Zagros Ranges (Miliaresis 2013a) and in Antarctica (Miliaresis 2014a).

The evaluation of the thematic information content of the multi-temporal thermal anomaly imagery is based on the interpretation of the spatial pattern (cluster maps) and the temporal pattern of cluster centroids (Miliaresis 2014a). The temporal pattern allows the terrain classification to regions presenting either positive or negative thermal anomaly but there are peaks affecting every centroid cluster curve. Local weather phenomena, snow melt, surface water flow, precipitation as well variation in water table depth could relate to the observed peaks. If this is true, then it will be possible to isolate the regional thermal 
anomaly component from the residual thermal anomaly component induced from local weather phenomena. The regional thermal anomaly component is more likely to relate to geology (lithology, thermal inertia of rocks) and geophysics (geothermal fields) of the study area. In addition, the expression of local weather phenomena (for example precipitation) in the temporal pattern of LST could provide a sort of evaluation of the precipitation data sets available.

Daymet data set provides monthly summary data at $1 \times 1 \mathrm{~km}$ spatial resolution for precipitation (Thornton et al. 1997). The single month summary data product is produced for each month for individual years and covers the period 1980-2014 (Thornton et al. 2015).

The aims of this research effort are: (1) to define the temporal and spatial pattern of night monthly averaged thermal anomalies in SW USA and (2) to quantify the temporal pattern of thermal anomalies in SW USA in relation to precipitation data, in attempt to reveal the possible relationship of thermal anomaly peaks to the precipitation pattern.

\section{Methodology}

In order to minimize the effect of $\mathrm{H}, \mathrm{LAT}$ and LON to the multi-temporal LST dataset a short of data transformation is required in order to produce a new set of images that should present high correlations to the three independent variables under consideration (Miliaresis 2012a). In this context, principal components analysis (PCA) is a linear transformation technique that produces a set of images known as principal components (PCs) that are uncorrelated with one another and are ordered in terms of the amount of variance (eigenvalues) they explain from the original image set (Jolliffe 2002). In previous research efforts (Miliaresis 2012b) PCs are computed from the linear combination of eigenvectors and the corresponding pixel values of the initial images (Mather and Koch 2011). The eigenvalues and eigenvectors are computed from the crosscorrelation matrix (Miliaresis 2012c). So thermal anomalies are expressed as normal scores and it is difficult to quantify positive versus negative thermal anomalies (Miliaresis 2013a, b, 2014a). The method is modified and the PCs are computed from variance-covariance matrix (Miliaresis 2016). Thus, the thermal anomaly per pixel expresses the deviation in degrees Celsius from the elevation, latitude, longitude predicted LST (Miliaresis 2016).

Finally, linear regression models are applied to the first two PCs and split the variance associated to H, LAT and LON that is included in the predicted images (Miliaresis 2013a). ANOVA table for each regression verify the statistical significance (Miliaresis 2013b). The model performance is further assessed by the $\mathrm{R}^{2}$ ( $\mathrm{R}$ is the multiple correlation coefficient between the independent variables and the dependent variable) that represents the extent of variability in the dependent variable explained by all the independents variables (Landam and Everitt 2004). Then, the multi-temporal data set is reconstructed by considering the residual images for the first 2 PCs as well as the later PCs (Miliaresis 2014a).

\section{Study area}

The study area (Fig. 1) is bounded by longitudes $-124^{\circ}$ to $-112^{\circ}$ (West) and latitudes $32^{\circ}-44^{\circ}$ (North) and includes the states of California, Nevada, Utah and Arizona. NW of the study area (California), the climate is characterized by moderately cold winters with heavy snowfall on the mountains (Sierra Nevada Ranges) and warm, very dry summers with limited rainfall, especially in the south (Wang and Gillies 2012).

The central and the eastern part of the study area (Nevada, Arizona and Utah) is mostly formed by a series of parallel mountain ranges intervening flat basins (Fig. 1). The climate is generally semi-arid or arid with warm summers and cold winters but this varies by location and elevation (Wang and Gillies 2012) since some mountainous areas are high enough in elevation to experience an Alpine climate. The majority of streams and rivers flow into desert sinks or closed-basin lakes while Colorado River crosses Grand Canyon in SE (Barnett and Pierce 2008). Southerly, the study area is occupied by Mojave Desert (California) and by Sonoran Desert (Arizona).

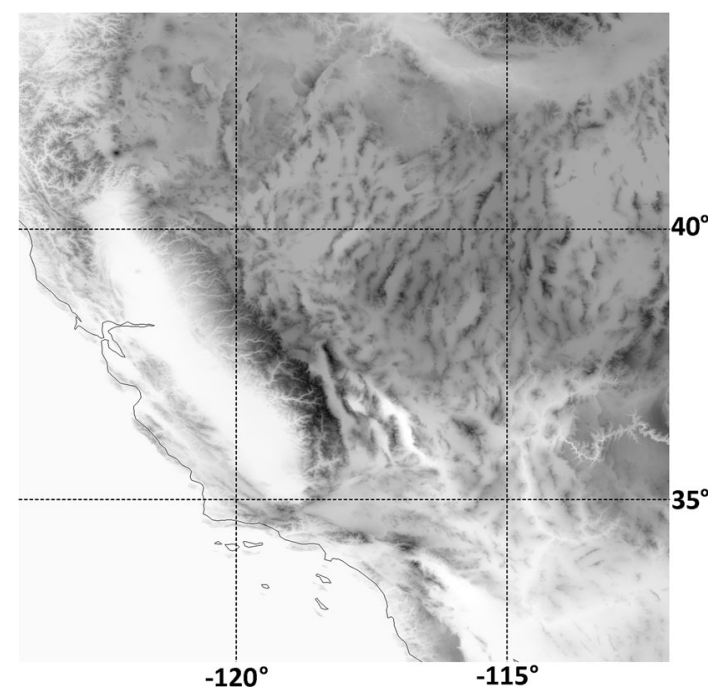

Fig. 1 Elevation map of the study area. The elevation values in the range $(-83,4092 \mathrm{~m}$ ) were rescaled in the range 255 (white) to 0 (black). The lighter a pixel, the lower its elevation 


\section{Data}

The SRTM30 digital elevation model (DEM) (Farr and Kobrick 2000) with spatial resolution equal to $0.00833^{\circ}$ (approximately $1 \mathrm{~km}$ at the equator) provides the elevation representation of the study area (Fig. 1). A geographic latitude/longitude grid is used with WGS 84 as horizontal datum (SRTM30 2015). The elevation range is in between -83 and $4097 \mathrm{~m}$. Negative elevations are observed in Death Valley, (California).

Around local solar time 01:30 (night), and 13:30 (day) LST data are acquired from the MODIS instrument on board the Aqua polar orbiting satellite (MYD11C2 2016). The LST accuracy according to Wan (2014) is better than $1 \mathrm{~K}(0.5 \mathrm{~K}$ in most cases) under real clear-sky conditions. Data from real clear-sky conditions within a calendar month are averaged to yield the MYD11C2 product (Wan 2013). The data set provide a continuous (monthly averaged LST) sampling of the earth's surface with a spatial resolution of $3 \mathrm{~min}\left(0.05^{\circ}\right.$, corresponding to $5.6 \mathrm{~km}$ approximately at the equator) referenced to a geographic latitude/longitude grid, with WGS 84 being the horizontal datum (MYD11C2 2016). The 12 night monthly averaged LST images for 2007 are visualized in Fig. 2.

Daymet data set provides monthly summary climate data for minimum and maximum temperature, precipitation, and vapor pressure (Thornton et al. 2015). Precipitation is the sum of all forms of precipitation converted to water equivalent ( $\mathrm{mm} / \mathrm{month}$ ) (Thornton et al. 2015). The Daymet data layers are produced on a $1 \times 1 \mathrm{~km}$ gridded surface over the conterminous United States in Lambert Conformal Conic projection (units are meters) with the following parameters, (1) horizontal datum: WGS 84, (2) 1st standard parallel $=25^{\circ}$, and 2nd standard parallel $=60^{\circ}$, (3) Central meridian $=-100^{\circ}$, and Latitude of origin $=42.5^{\circ}$, (4) false easting $=0$, false northing $=0$. The 12 Daymet gridded monthly precipitation $(\mathrm{P})$ images for the year 2007 are used (Fig. 3). The precipitation and the SRTM data were resampled by bi-linear interpolation to the MYD11C2 spatial grid, that is also called the Climatic Modeling Grid (CMG).

\section{Selective variance reduction}

The variance-covariance matrix is used for the computation of PCs (Table 1) thus the reconstructed LST imagery express thermal anomalies in degrees Celsius (Miliaresis 2016). The contribution of the independent variables $(H$, LAT, LON) to PC1 and PC2 (dependent variables) is quantified by the linear regression models (Eqs. 1, 2).

$$
\begin{aligned}
\mathrm{PC} 1= & 135.85198-0.011758 \times \mathrm{H}-3.39332 \times \mathrm{LAT} \\
& -0.22067 \times \mathrm{LON}
\end{aligned}
$$

$\mathrm{PC} 2=-186.8823+0.00048079 \times \mathrm{H}-0.360232$

$$
\times \text { LAT }-1.47717 \times \text { LON }
$$

The $\mathrm{R}^{2}$ (Table 2) indicates the amount of variance explain by the multiple lineal regression models (Landam and Everitt 2004).

The analysis of variance (ANOVA) tables for Eqs. 1, 2 are presented in Table 2. The F-statistic and the t-statistic (Landam and Everitt, 2004) combined are used in estimating, a) the success of the regression models and b) for adding or deleting variables (the significance of independent variables), respectively. The $F$ test value for Eq. 1 indicates the overall significance of the regression, since it far exceeds the F-critical value (26.12) at the 0.01 significance level. For Eq. 1, the coefficients for H, LAT and LON express the individual contribution of the independent variable to PC1. The absolute values of the $t$ test for the 3 independent variables far exceed the t-critical value (2.58) at two tailed 0.01 significance level and hence their coefficients depart significantly from 0 . The ANOVA table (Table 2) for Eq. 2 also verifies the overall significance of the multiple regression model for PC2, as well as the significance of the 3 independent variables.

The 12 night monthly averaged reconstructed LST (RLST) images for 2007 are visualized in Fig. 4.

\section{Thematic information content}

Clustering will reveal the thematic information content of the RLST imagery (Fig. 4). The underlying idea is that the temporal (centroids), and the spatial patterns (maps) of clusters will reveal regions with similar (negative or positive) LST anomalies (Miliaresis 2013a). K-Means clustering was implemented in SPSS (Landam and Everitt 2004). It begins by initializing centroids, assigns each pixel to the cluster whose centroid is nearest, updates centroids, then repeats the process until there is no overall change in cluster centers.

Eight clusters (Fig. 5) were mapped (spatial pattern). A sort of clustering evaluation is given in Table 3 . The divergence (Table 3 ) determines the degree of separation of pairs of clusters on the basis of the Euclidean distance of their centroids. The centroids (temporal pattern), are presented in Table 4 and in Fig. 6. The precipitation per month per cluster is presented in Fig. 7 and in Table 5.

\section{Discussion of results}

The first 2 PCs accounts for the $97.4 \%$ of the variance evident within the multi-temporal imagery (Table 1) while PC-3 to PC-12 components account only for the $2.6 \%$ of the total variance evident in the initial data. The Eqs. 1, 2 

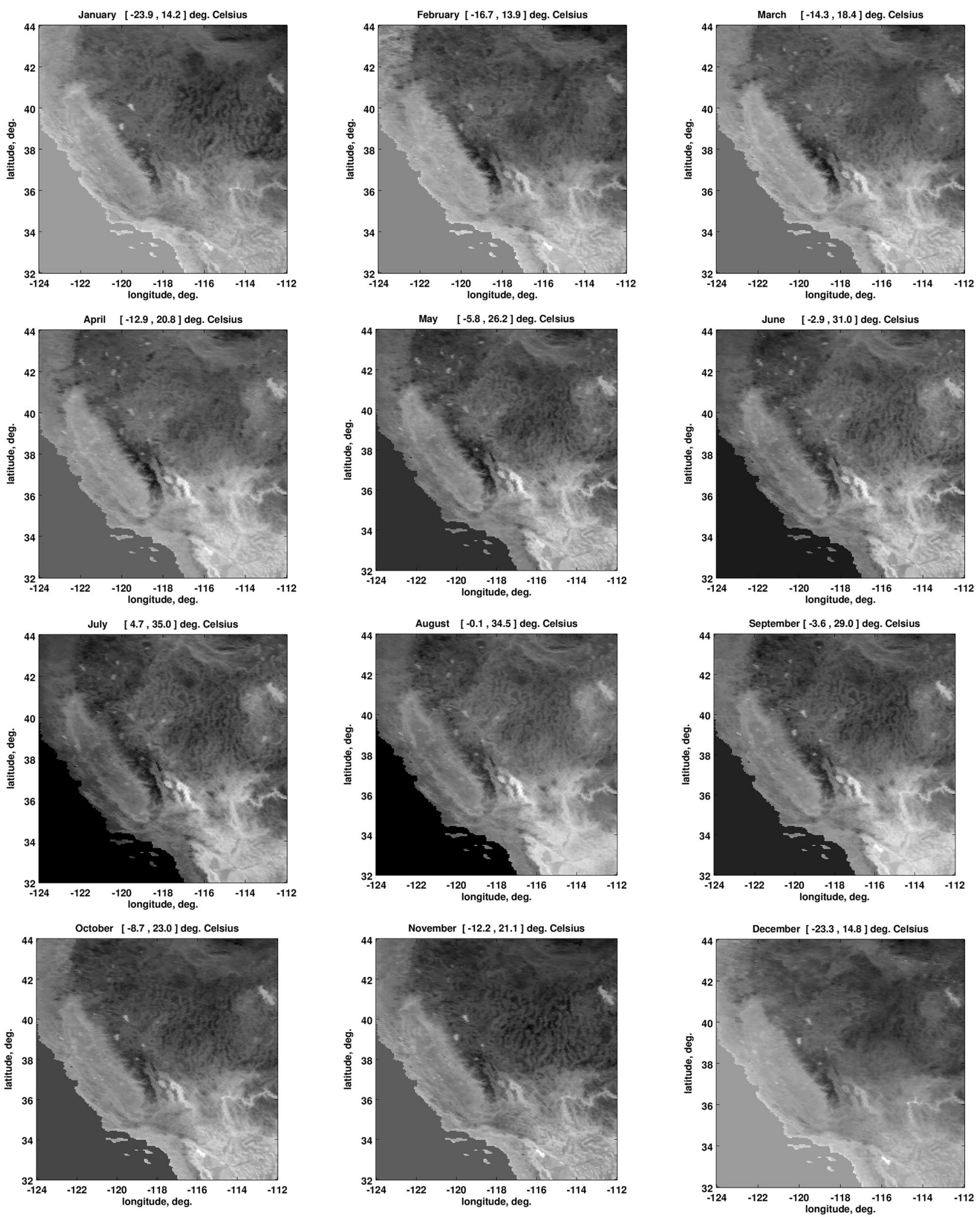

Fig. 2 The monthly averaged night LST imagery of the study area for the year 2007. Each image is rescaled to it's minimum (black) and it's maximum (white) in attempt to reveal negative (black pixels) and positive (white pixels) LST outliers 

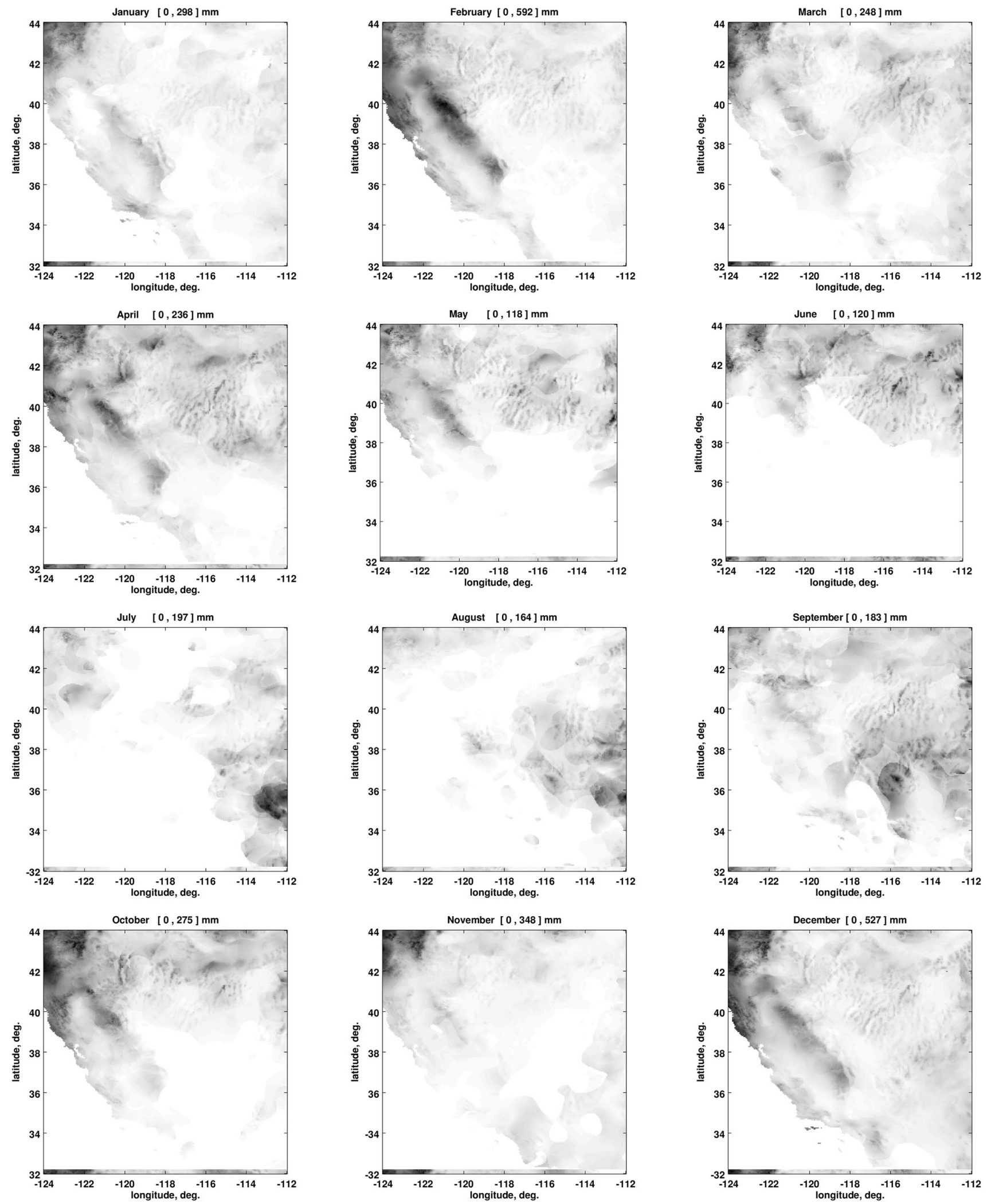

Fig. 3 The monthly averaged precipitation imagery of the study area for the year 2007 reprojected and resampled to the CMG. Each image is rescaled to it's minimum (white) and it's maximum (black) in attempt to reveal precipitation outliers 
Table 1 Eigenvectors, eigenvalues and principal components (PCs) of the multi-temporal LST data

\begin{tabular}{|c|c|c|c|c|c|c|c|c|c|c|c|c|}
\hline \multirow[t]{2}{*}{ Eigen vectors } & \multicolumn{12}{|c|}{ Principal components (PCs) } \\
\hline & $\mathrm{PC} 1$ & PC2 & PC3 & PC4 & PC5 & PC6 & PC7 & PC 8 & PC9 & PC10 & PC11 & PC12 \\
\hline 1 & 0.32 & 0.45 & 0.46 & 0.55 & -0.27 & -0.12 & 0.14 & 0.20 & -0.06 & -0.12 & -0.13 & -0.04 \\
\hline 2 & 0.29 & 0.20 & -0.39 & 0.08 & 0.25 & -0.67 & -0.42 & 0.09 & 0.08 & 0.11 & 0.02 & 0.00 \\
\hline 3 & 0.29 & 0.08 & -0.34 & 0.26 & 0.16 & 0.09 & 0.37 & -0.72 & 0.04 & -0.15 & -0.03 & -0.09 \\
\hline 4 & 0.29 & -0.10 & -0.45 & 0.08 & 0.09 & 0.19 & 0.35 & 0.54 & -0.45 & 0.00 & 0.19 & -0.07 \\
\hline 5 & 0.27 & -0.21 & -0.08 & 0.21 & -0.03 & 0.27 & -0.15 & 0.15 & 0.52 & -0.24 & 0.24 & 0.57 \\
\hline 6 & 0.25 & -0.36 & -0.03 & 0.19 & 0.03 & 0.32 & -0.47 & 0.05 & 0.02 & -0.13 & -0.43 & -0.49 \\
\hline 7 & 0.21 & -0.44 & 0.14 & 0.24 & -0.22 & -0.10 & 0.02 & -0.17 & -0.07 & 0.74 & 0.18 & 0.05 \\
\hline 8 & 0.26 & -0.40 & 0.18 & -0.23 & -0.17 & -0.34 & -0.03 & -0.16 & -0.46 & -0.44 & -0.12 & 0.31 \\
\hline 9 & 0.30 & -0.19 & 0.21 & -0.33 & -0.02 & -0.24 & 0.31 & 0.12 & 0.45 & -0.15 & 0.28 & -0.49 \\
\hline 10 & 0.30 & 0.05 & 0.11 & -0.30 & 0.33 & 0.06 & 0.28 & 0.13 & 0.16 & 0.30 & -0.64 & 0.28 \\
\hline 11 & 0.32 & 0.22 & 0.39 & -0.18 & 0.48 & 0.29 & -0.29 & -0.14 & -0.27 & 0.07 & 0.41 & -0.01 \\
\hline 12 & 0.34 & 0.35 & -0.24 & -0.44 & -0.64 & 0.22 & -0.18 & -0.11 & 0.00 & 0.12 & -0.01 & -0.01 \\
\hline Eigen-value & 335.5 & 34.24 & 3.307 & 1.677 & 1.363 & 1.037 & 0.706 & 0.459 & 0.409 & 0.371 & 0.325 & 0.214 \\
\hline$\%$ & 88.38 & 9.02 & 0.87 & 0.44 & 0.36 & 0.27 & 0.19 & 0.12 & 0.11 & 0.10 & 0.09 & 0.06 \\
\hline
\end{tabular}

The last line indicate the percent variance explain by each PC

Table 2 ANOVA tables for Eq. 1 and Eg. 2 (d.f = degrees of freedom)

\begin{tabular}{|c|c|c|c|c|c|c|c|c|c|}
\hline \multicolumn{5}{|c|}{$\mathrm{R}^{2}=0.802$, ANOVA regression table for Eq. 1} & \multicolumn{5}{|c|}{$\mathrm{R}^{2}=0.601$, ANOVA regression table for Eq. 2} \\
\hline Source & d.f & Sum of squares & Mean square & $F$ test & Source & d.f & Sum of squares & Mean square & $F$ test \\
\hline Regression & 3 & 12972567 & 4324189 & 65043 & Regression & 3 & 992457 & 330819 & 24223 \\
\hline Residual & 48220 & 3205748 & 66.482 & & Residual & 48220 & 658528 & 13.65 & \\
\hline Total & 48223 & 16178315 & & & Total & 48223 & 1650986 & & \\
\hline \multicolumn{4}{|c|}{ Individual regression coefficients for Eq. 1} & & & \multicolumn{4}{|c|}{ Individual regression coefficients for Eq. 2} \\
\hline \multicolumn{3}{|c|}{ Independent variable } & $\begin{array}{l}t \text { test, d.f. } \\
48220\end{array}$ & & & \multicolumn{3}{|c|}{ Independent variable } & $\begin{array}{l}t \text { test, d.f. } \\
48220\end{array}$ \\
\hline \multicolumn{3}{|l|}{$\mathrm{H}$} & -197.625 & & \multicolumn{3}{|c|}{$\mathrm{H}$} & \multicolumn{2}{|r|}{17.830} \\
\hline \multicolumn{3}{|l|}{ LAT } & -249.207 & & \multicolumn{3}{|c|}{ LAT } & \multicolumn{2}{|r|}{-58.371} \\
\hline \multicolumn{3}{|l|}{ LON } & -17.319 & & \multicolumn{3}{|c|}{ LON } & \multicolumn{2}{|r|}{-255.804} \\
\hline
\end{tabular}

explain $76.12 \%$ of the total variance evident in the multitemporal LST data. More specifically:

- For Eq. 1, R2 equals to 0.802 (Table 2). Thus, according to the PC1 eigenvalue (percent variance of PC1 equals to $88.38 \%$ in Table 1), the $70.8 \%$ $(0.802 \times 88.38 \%)$ of the total variance of the LST data is explained by Eq. 1 .

- For Eq. 2, R2 equals to 0.601 (Table 2). Thus, according to the PC2 eigenvalue (the percent variance of PC2 equals to $9.02 \%$ in Table 1$)$, the $5.42 \%(0.601 \times 9.02 \%)$ of the total variance of the LST data is explained by Eq. 2 .

Thus, the two residual images for $\mathrm{Eq} 1$ and $\mathrm{Eq} 2$ accounts for the $17.58 \%(88.38-70.8)$ and $3.6 \%$ (9.02-5.42), respectively, of the total variance evident in the multi-temporal dataset. So the RLST imagery (Fig. 4) accounts only for the $23.78 \%(17.58+3.6+2.6 \%)$ of the total variance of the initial data that is independent of $\mathrm{H}, \mathrm{LAT}$ and LON.

The interpretation of Fig. 2 indicate that regions with high LST values (white regions) are observed in Death Valley, in Grand Canyon, in Sonoran Desert and in isolated lakes in Northern West Nevada. Since the imagery was acquired during the night, water surfaces, playa lakes (seasonally covered by water,) and regions where the water table is very high present greater LST than regions where LST is minimized during the night. According to Fig. 2 the coastal regions (West of Sierra Nevada) as well as the southern regions (Mojave and Sonoran Deserts) do present higher LST than the NE regions of Nevada and Utah. 

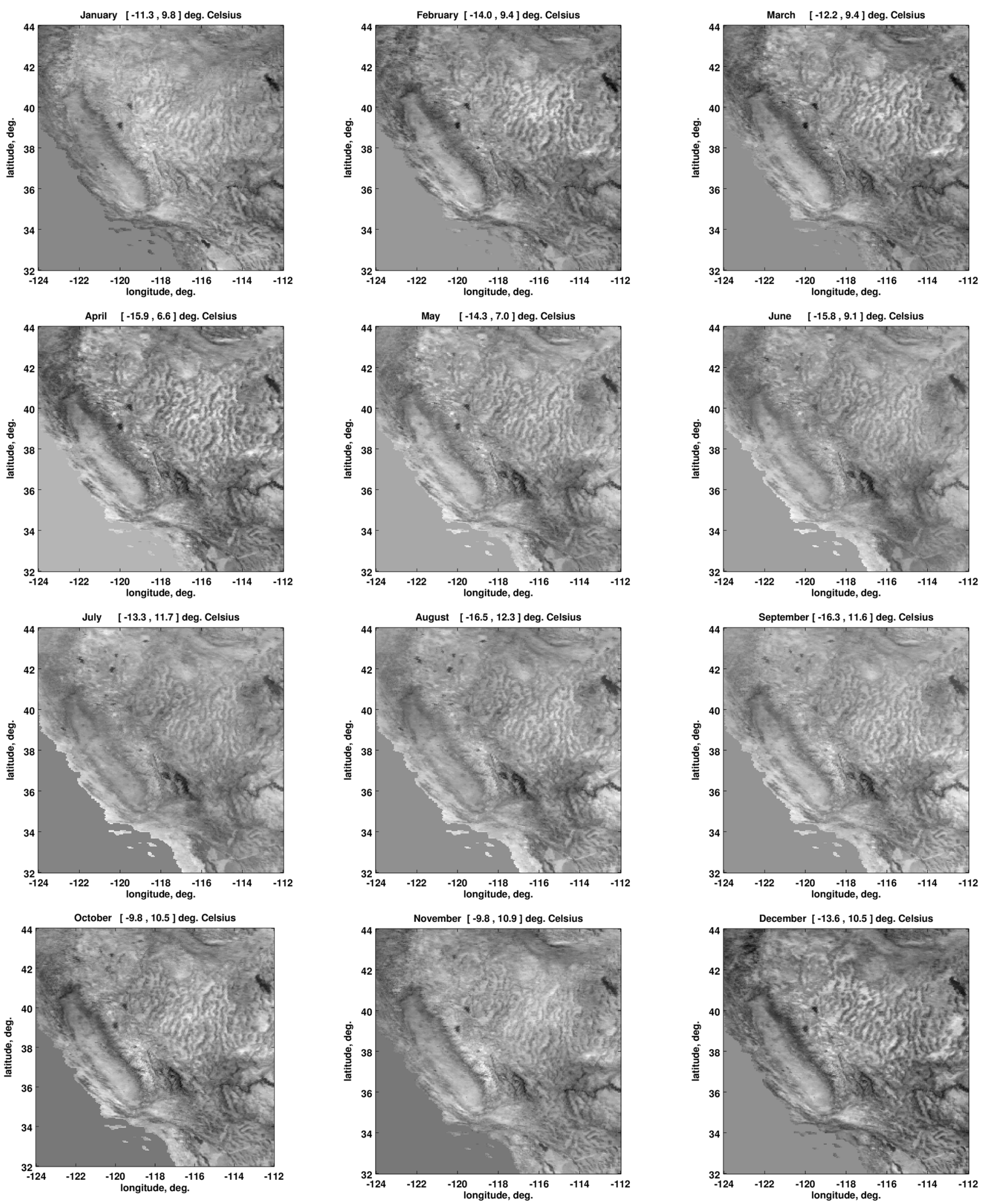

Fig. 4 The monthly averaged RLST (thermal anomaly) imagery of the study area for the year 2007, indicating the deviation per pixel in degrees Celsius, from the elevation, latitude, longitude predicted LST.
Each image is rescaled to it's minimum (black) and it's maximum (white) in attempt to reveal negative (black pixels) and positive (white pixels) RLST outliers 
Fig. 5 The spatial pattern of the 8 RLST clusters. The clusters are group according to the cluster centroids (Fig. 5) to those presenting rather positive thermal anomaly (left map) and those with rather negative thermal anomaly (right map)
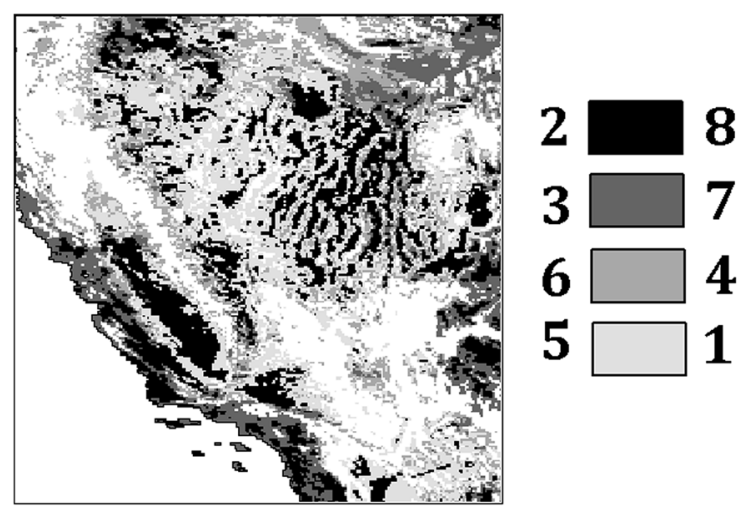

Table 3 Divergence: distances between final cluster centers

\begin{tabular}{|c|c|c|c|c|c|c|c|c|}
\hline \multicolumn{9}{|l|}{ Cluster } \\
\hline Cluster & 1 & 2 & 3 & 4 & 5 & 6 & 7 & 8 \\
\hline 1 & 0 & 16.8 & 9.1 & 7.2 & 4.6 & 10.1 & 6.3 & 13.8 \\
\hline 2 & 16.8 & 0 & 8.3 & 18.2 & 13.7 & 9.1 & 22.1 & 28.9 \\
\hline 3 & 9.1 & 8.3 & 0 & 12.8 & 7.4 & 6.8 & 15.0 & 22.4 \\
\hline 4 & 7.2 & 18.2 & 12.8 & 0 & 5.5 & 9.1 & 6.0 & 11.0 \\
\hline 5 & 4.6 & 13.7 & 7.4 & 5.5 & 0 & 5.7 & 8.4 & 15.3 \\
\hline 6 & 10.1 & 9.1 & 6.8 & 9.1 & 5.7 & 0 & 13.9 & 20.1 \\
\hline 7 & 6.3 & 22.1 & 15.1 & 6.0 & 8.4 & 13.9 & 0 & 7.5 \\
\hline 8 & 13.8 & 28.9 & 22.4 & 11.0 & 15.3 & 20.1 & 7.5 & 0 \\
\hline
\end{tabular}

The interpretation of the seasonal variation of precipitation (Fig. 3) indicate the influence of Sierra Nevada (rain shadow East of Sierra Nevada) to the spatial distribution precipitation (note that gray look up table is reverted in Fig. 3, thus white regions indicate zero precipitation). The temporal pattern indicates no or limited precipitation during the summer period for the coastal and southern regions (Fig. 3).

The RLST imagery (Fig. 4) indicate that in terms of thermal anomaly, the Death Valley, Grand Canyon and the lakes present a negative thermal anomaly (dark tones in Fig. 4) almost through out the year. So surface water flow (for examples exotic rivers like the Colorado River) as well as seasonal lakes (due to snow melting on mountain ranges) do create negative thermal anomalies in the terrain. On the other hand positive thermal anomalies (white regions in the RLST imagery in Fig. 4) dominate many (possibly dry) basins intervening the mountain ranges in Nevada, as well as the rain shadow region east of Sierra Nevada and the southern coastal zone.

Clustering defines 8 regions with distinct spatial extent (Fig. 5) and temporal thermal anomaly pattern (Fig. 6). For example the greatest positive thermal anomaly is observed in Fig. 6 (left) for the basins in the central Nevada and the peneplain west of Sierra Nevada (Fig. 5).

On the other hand, the temporal pattern in Fig. 6 do reveal the existence of local thermal anomaly maxima (peaks) and minima that do persist in almost every centroid curve. For example the local minima in April and in December and the local maxima in March and in November (Fig. 6). Mean precipitation per month per cluster is computed in Table 5 and presented in Fig. 7. Precipitation peaks in February and December (Fig. 7) seems to be responsible for the corresponding thermal anomaly minima in Fig. 6. The fluctuations in precipitation curves in Fig. 7 seem to interpret almost every opposite in sign fluctuation of the thermal anomaly centroid curves in Fig. 6.

Table 4 RLST cluster centroids

\begin{tabular}{lrrrrrrrrrrrr}
\hline Cluster & \multicolumn{1}{l}{ Jan } & \multicolumn{1}{c}{ Feb } & \multicolumn{1}{c}{ Mar } & \multicolumn{1}{c}{ Apr } & \multicolumn{1}{c}{ May } & \multicolumn{1}{c}{ Jun } & Jul & Aug & Sep & Oct & Nov & Dec \\
\hline 1 & -2.26 & -4.06 & -2.67 & -5.09 & -2.28 & -1.19 & 1.88 & 0.76 & 0.61 & 0.37 & 0.17 & -4.69 \\
2 & 2.87 & 2.12 & 2.82 & 0.61 & 1.73 & 2.03 & 4.15 & 4.48 & 4.94 & 4.99 & 4.91 & 2.35 \\
3 & -0.41 & -1.35 & -0.06 & -1.70 & 0.37 & 1.46 & 4.16 & 3.46 & 3.35 & 2.91 & 2.40 & -1.73 \\
4 & 1.07 & -2.55 & -1.94 & -5.64 & -3.69 & -3.84 & -1.13 & -2.32 & -1.50 & -0.14 & 0.87 & -2.34 \\
5 & 0.62 & -2.41 & -1.39 & -4.40 & -1.97 & -1.46 & 1.30 & 0.24 & 0.68 & 1.12 & 1.72 & -2.58 \\
6 & 2.89 & 0.00 & 0.54 & -2.77 & -1.07 & -1.13 & 1.24 & 0.84 & 1.59 & 2.45 & 3.33 & 0.50 \\
7 & -1.79 & -4.89 & -3.88 & -7.19 & -4.11 & -3.74 & -0.50 & -2.01 & -1.72 & -1.29 & -0.68 & -5.85 \\
8 & -2.08 & -6.02 & -5.20 & -8.99 & -6.49 & -6.39 & -3.47 & -5.62 & -4.92 & -3.24 & -2.12 & -6.38 \\
\hline
\end{tabular}




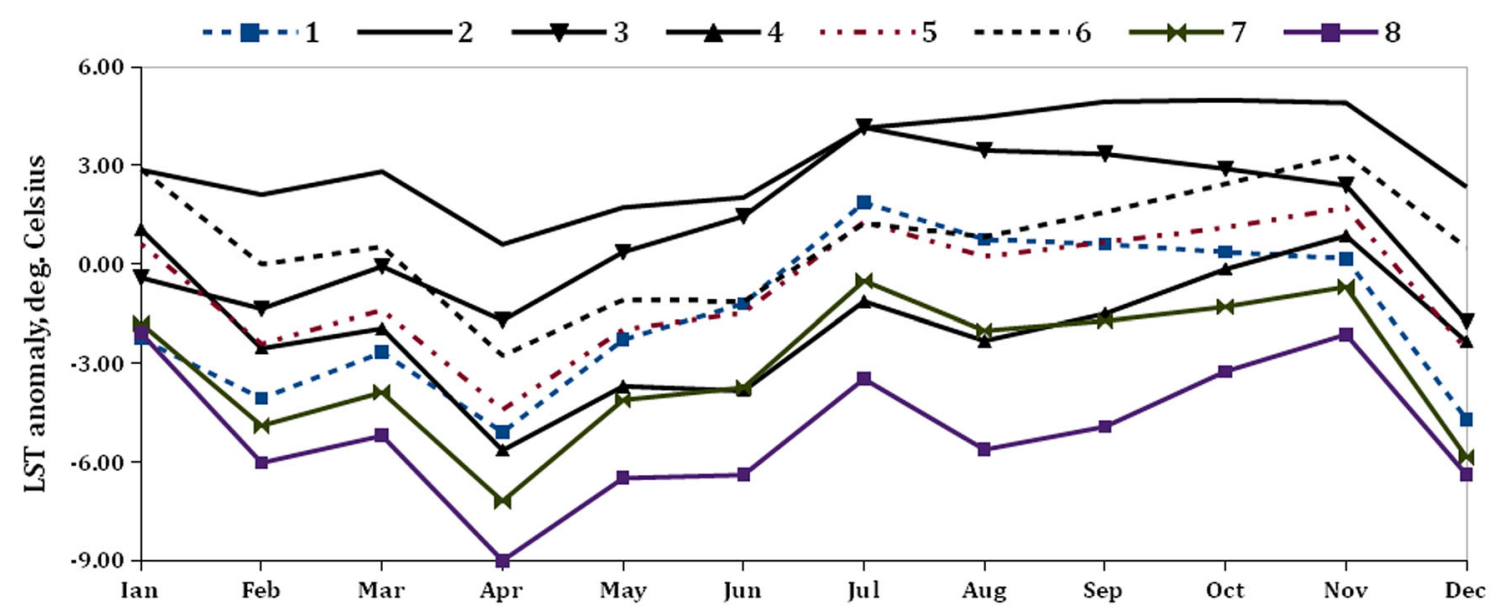

Fig. 6 The 8 RLST cluster centroids

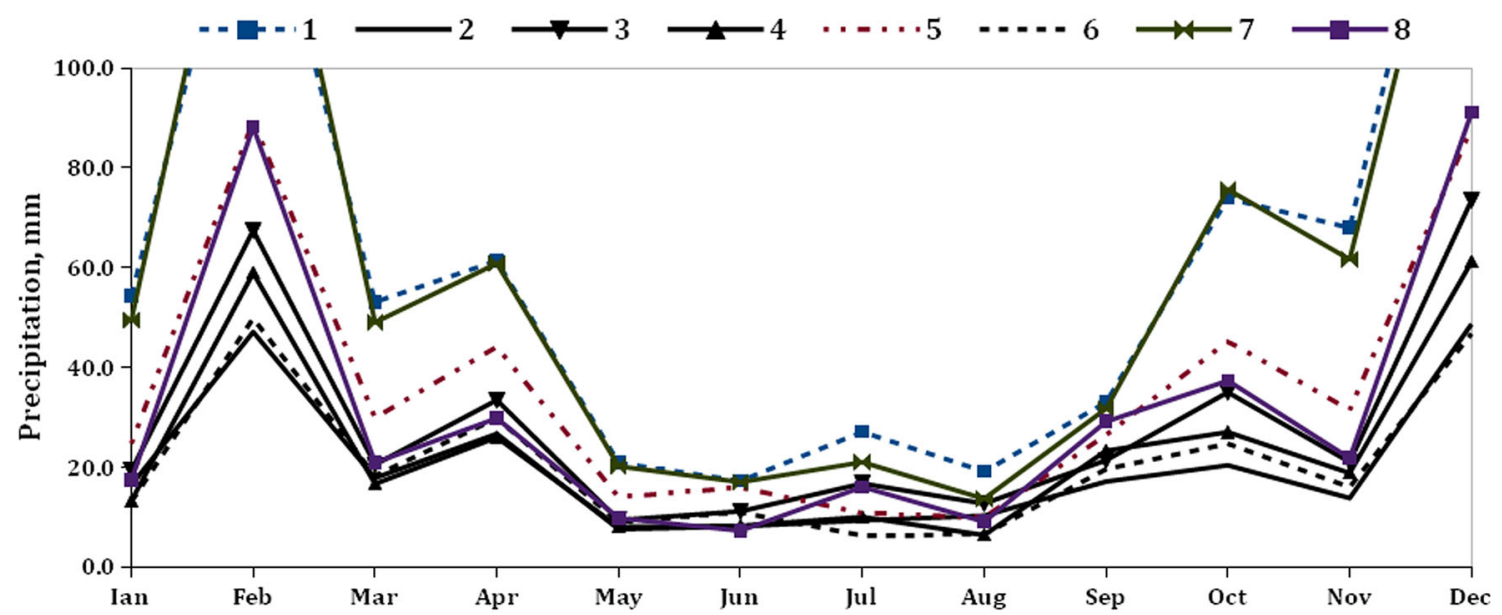

Fig. 7 Mean precipitation per month per cluster. The maximum precipitation in $Y$ axis equals to $100 \mathrm{~mm}$ per month to allow the better discrimination among clusters during the summer. For December and
February the clusters 1 and 7 (Table 5) (presenting precipitation far greater than $100 \mathrm{~mm}$ per month) are projected outside the graphic area

Table 5 Mean precipitation per month, per cluster

\begin{tabular}{lllllllllllll}
\hline Cluster & Jan & Feb & Mar & Apr & May & Jun & Jul & Aug & Sep & Oct & Nov & Dec \\
\hline 1 & 54.4 & 149.5 & 53.1 & 61.4 & 20.9 & 17.3 & 27.1 & 19.2 & 33.0 & 73.9 & 68.0 & 169.7 \\
2 & 16.5 & 47.2 & 17.9 & 26.8 & 7.6 & 8.2 & 9.4 & 10.4 & 17.2 & 20.4 & 13.9 & 48.7 \\
3 & 19.4 & 67.5 & 20.6 & 33.5 & 9.5 & 11.2 & 16.8 & 12.8 & 21.5 & 35.1 & 21.1 & 73.6 \\
4 & 13.3 & 59.0 & 16.7 & 26.0 & 8.1 & 8.3 & 10.1 & 6.5 & 23.3 & 27.1 & 18.9 & 61.2 \\
5 & 24.8 & 89.4 & 30.0 & 44.2 & 14.0 & 16.0 & 10.9 & 10.0 & 26.5 & 45.3 & 31.6 & 88.1 \\
6 & 13.1 & 49.9 & 18.4 & 29.9 & 9.0 & 11.0 & 6.4 & 6.6 & 19.7 & 24.8 & 16.1 & 46.8 \\
7 & 49.5 & 161.6 & 49.1 & 60.9 & 20.2 & 17.1 & 21.1 & 13.7 & 31.8 & 75.7 & 61.7 & 159.6 \\
8 & 17.5 & 88.2 & 21.0 & 29.9 & 9.9 & 7.3 & 16.1 & 9.1 & 29.2 & 37.4 & 21.9 & 91.1 \\
\hline
\end{tabular}

\section{Conclusion}

The selective variance reduction technique that applies linear regression models to the principal components of multi-temporal night monthly averaged land surface temperature imagery split the variance associated to elevation, latitude, longitude in SW USA for the year 2007. The reconstructed multi-temporal imagery indicate the positive or negative deviation (thermal anomaly) from the elevation, latitude, longitude predicted LST. The spatial 
and temporal patterns of thermal anomalies are revealed by $\mathrm{K}$-means clustering. The mean precipitation computed per month per cluster interpreted the observed fluctuations in the temporal pattern of thermal anomaly.

In addition to precipitation, snow melting, surface water flow, as well variation in water table depth could relate to the observed peaks. It seams that it is possible to isolate the regional thermal anomaly component from the residual thermal anomaly component induced from local weather phenomena. The regional thermal anomaly component is more likely to relate to geology (lithology and thermal inertia of rocks) and geophysics (geothermal fields) of the study area. The quantification of the influence of precipitation to the temporal pattern of LST could provide a sort of evaluation of the precipitation data sets available.

\section{References}

Barnett TP, Pierce DW (2008) When will lake Mead go dry? Water Resour Res 44:W03201. doi:10.1029/2007WR006704

Farr TG, Kobrick M (2000) Shuttle radar topography mission produces a wealth of data. Am Geophys Union EOS 81:583-585

Jolliffe I (2002) Principal component analysis, 2nd edn. Springer, New York

Landam S, Everitt BS (2004) A handbook for statistical analysis using SPSS. Chapman and Hall/CRC Press, New York

Mather PM, Koch M (2011) Computer processing of remotely sensed images, 4th edn. John Wiley and Sons, New York

Miliaresis G (2009) Regional thermal and terrain modeling of the Afar depression from multi-temporal night LST data. Int J Remote Sens 30:2429-2446

Miliaresis G (2012a) Elevation, latitude/longitude decorrelation stretch of multi-temporal LST imagery. Int J Remote Sens 33:6020-6034

Miliaresis G (2012b) Elevation, latitude/longitude decorrelation stretch of multi-temporal LST imagery. Photogramm Eng Remote Sens 78:151-160
Miliaresis G (2012c) Selective variance reduction of multi-temporal LST imagery in the East Africa Rift System. Earth Sci Inf 5:1-12

Miliaresis G (2013a) Terrain analysis for active tectonic zone characterization, a new application for MODIS night LST (MYD11C2) dataset. Int J Geogr Inf Sci 27:1417-1432

Miliaresis G (2013b) Thermal anomaly mapping from night MODIS imagery of USA, a tool for environmental assessment. Environ Monit Assess 185:1601-1612

Miliaresis G (2014a) Spatiotemporal patterns of land surface temperature of Antarctica from MODIS monthly LST data (MYD11C2). J Spat Sci 59:157-166

Miliaresis G (2014b) Daily temperature oscillation enhancement of multi-temporal LST imagery. Photogramm Eng Remote Sens $80: 423-428$

Miliaresis G (2016) Selective variance reduction, octave implementation. SourceForge Project, http://selective-variance-reduction. sourceforge.net. Accessed 17 Feb 2016

MYD11C2 (2016) Aqua-MODIS monthly LST imagery, version 006. http://e4ft101.cr.usgs.gov/MOLA/MYD11C2.006/. Accessed 17 Feb 2016

SRTM30 (2015) SRTM30 Digital Elevation Model, Version 2.1. US Geological Survey. http://e4ft101.cr.usgs.gov/SRTM/ SRTMGL30.002/. Accessed 17 Feb 2016

Thornton PE, Running SW, White MA (1997) Generating surfaces of daily meteorological variables over large regions of complex terrain. J Hydrol 190:214-251

Thornton PE, Thornton MM, Mayer BW, Wilhelmi N, Wei Y, Devarakonda R, Cook RB (2015) Daymet: monthly climate summaries on a $1 \mathrm{~km}$ Grid for North America, Version 2. Data set. Available on-line [http://daac.ornl.gov] from Oak Ridge National Laboratory Distributed Active Archive Center, Oak Ridge, Tennessee, USA. http://dx.doi.org/10.3334/ORNL DAAC/1281. Accessed 17 Feb 2016

Wan Z (2013) Collection-6, MODIS land surface temperature products. Users' Guide. University of California, Santa Barbara. http://www.icess.ucsb.edu/modis/LstUsrGuide/MODIS_LST_ products_Users_guide. Accessed 17 Feb 2016

Wan Z (2014) New refinements and validation of the Collection-6 MODIS land-surface temperature/emissivity products. Remote Sens Environ 140:36-45

Wang SYS, Gillies RR (2012) Climatology of the U.S. inter-mountain West. In: Shih-Yu Wang (ed) Modern climatology. InTech. doi: $10.5772 / 33940$ 